\title{
Agglomeration Economies
}

\author{
Jason Cao, Michael Iacono, David Levinson, and Mengying Cui
}

Abstract: Economists have long recognized the importance of urban areas as focal points of economic production and exchange. In recent decades, they have also come to better understand the productivity benefits of firms being located in large urban areas. A variety of advantages may accrue to firms that cluster together in large cities relating, for example, to access to specialized labor, information spillovers, and interactions with customers or suppliers. These types of advantages are often referred to as examples of agglomeration economies in urban areas. Empirically, these gains have been shown to be potentially quite large, with reviews of the literature suggesting that doubling the size of an urban area's population may be associated with productivity gains on the order of several percentage points.

While economic research on this topic has greatly advanced our understanding of the concepts, theory, and likely quantitative implications for urban economies, there has been comparatively little emphasis on the spatial nature of agglomeration economies within urban areas. This is an important distinction, as different sources of agglomeration economies may have different spatial characteristics, and some may be sensitive to transport costs in ways that can be affected by the performance of urban transportation networks. Our research was an effort to link these concepts by operationalizing two specific types of agglomeration economies, localization and urbanization economies, and to investigate their relationship to employment density across several economic sectors within the Twin Cities.

A gglomeration economies are, at their base, types of external scale economies that are common to urban locations. A useful way to distinguish agglomeration economies is to place them within a broader classification framework for economies of scale. As shown in Table 1, firms located in urban areas might exploit 12 different types of scale economies.

The scale economies that are associated with agglomeration processes are often referred to as "external" economies, since they mostly arise from sources outside of a given firm's

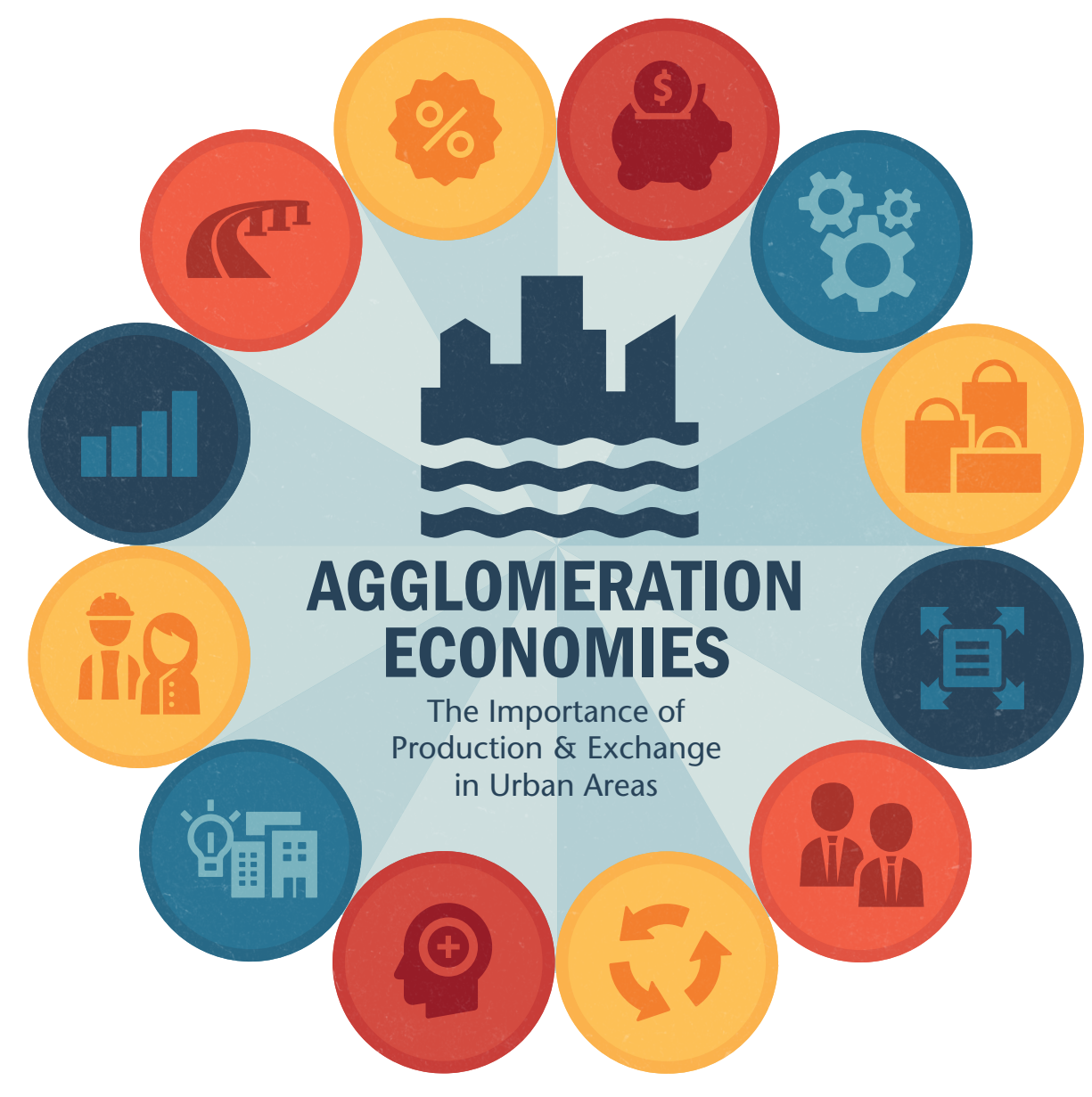

operations. Agglomeration economies can be further classified as either localization or urbanization economies. Table 1 lists four examples of each, classifying them again according to whether they are static or dynamic in nature. In addition to urbanization and localization effects, there are also "pure" agglomeration effects, which can arise from the spreading of fixed costs for shared inputs such as urban infrastructure.

The first example of localization economies relates to "shopping" economies in urban areas. Put simply, shoppers are attracted to places featuring many sellers. In principle, this concept could apply to both households and firms. At a small geographic scale, households may frequently visit shopping malls that feature many sellers and a variety of goods. At a larger scale, firms in a given industry may wish to locate in larger urban areas where they can have greater access to upstream suppliers of certain inputs. A related source of localization economies is the returns from economic specialization, which are commonly associated with the work of the early economist Adam Smith in his seminal work The Wealth of Nations. They are characterized in terms of the outsourcing of some activities within the production process, which allows both upstream suppliers of inputs and downstream firms to exploit the productivity gains from economic specialization.

Another type of localization effect is the economies that arise from labor pooling. These economies are sometimes referred to as "Marshallian" labor pooling in reference in an early (1890) text by English economist Alfred Marshall, which is considered to be foundational in the literature on agglomeration economies. The 


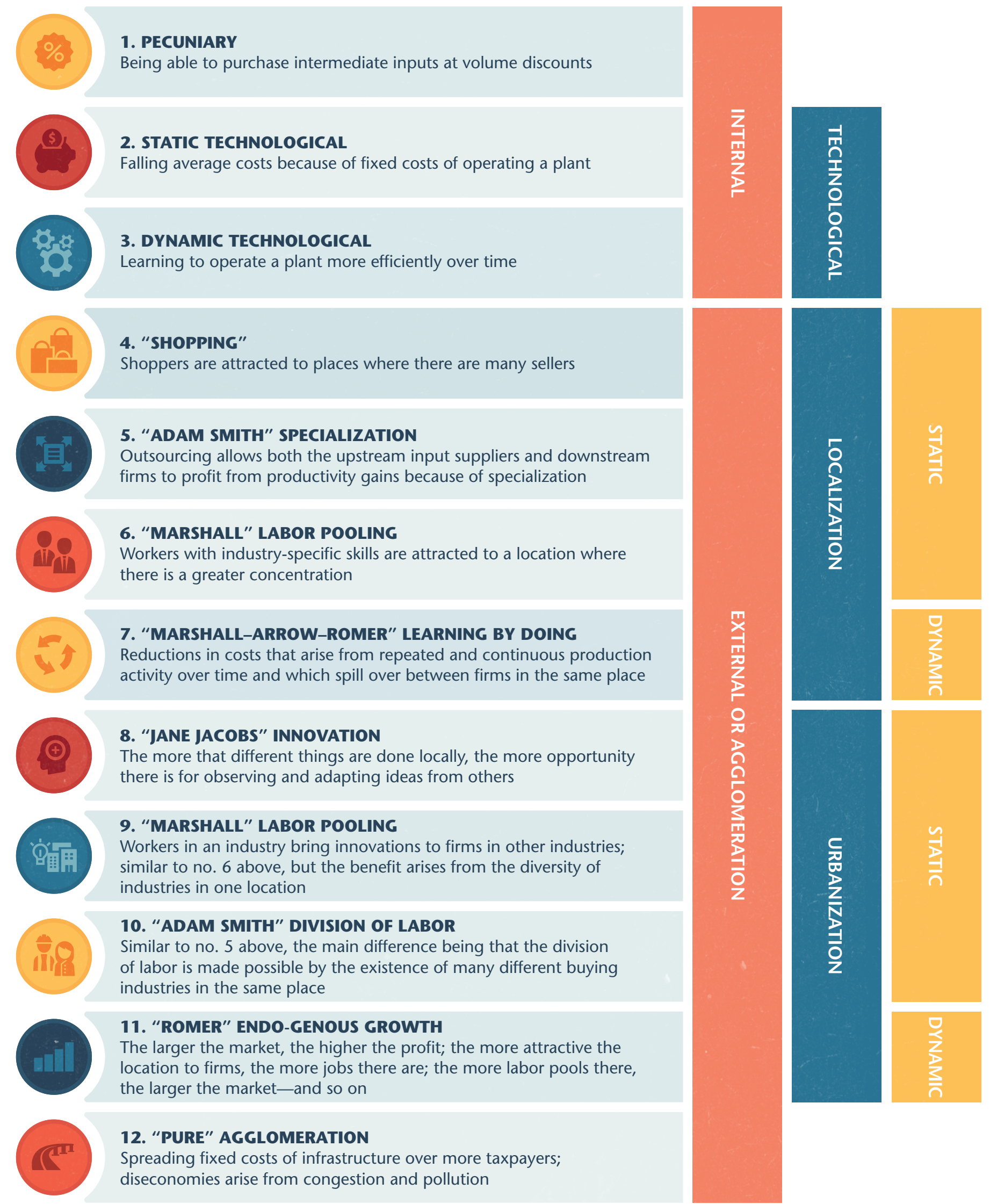

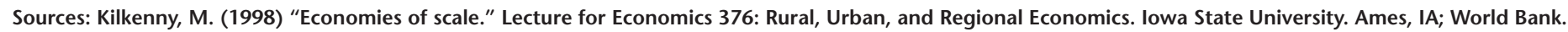
(2009) World Development Report: Reshaping Economic Geography. Report No. 43738. Washington, D.C.: The World Bank. 
localization type of economy from labor pooling relates to the phenomenon of workers with industry-specific skills being attracted to a location where there is a greater concentration of that industry.

While the previous three types of localization economies are static in nature, the fourth is more dynamic in that it emerges from continuous and repeated production activity over time. These "learning by doing" economies are analogous to the internal dynamic technological scale economies, though they differ in that they tend to operate at the level of an entire industry and to manifest themselves through knowledge spillovers between competing firms.

Urbanization economies are distinct in that they tend to be external to both firms and industries but occur because industries concentrate in an urban area. Some of the agglomeration economies associated with urbanization arise from the same sources as the localization economies just discussed, such as labor pooling and specialization, yet apply more broadly to all industries within an urban area. Several of the agglomeration economies arising from urbanization relate to the process of innovation within urban areas.

In addition to localization and urbanization economies, certain "pure" agglomeration economies are available to firms and households within urban areas. These relate to the ability to spread the fixed costs of certain urban goods, such as infrastructure, over a larger number of users. Of course, there are also potential diseconomies from increasing city size. Without well-managed and well-maintained transportation networks, for example, the benefits from agglomeration can be offset by diseconomies due to congestion, pollution, or other byproducts of increasing city size.

\section{Measuring Agglomeration}

Until fairly recently, much of the empirical work attempting to measure agglomeration economies tended to assume implicitly that agglomeration economies were largely due to urbanization effects and operated at a regionwide level. Our research differed in that we looked inside a particular urban area, the Twin Cities, and incorporated the region's transportation network to account for variations in access to other firms and consumers by location. Using specific measures of regional accessibility, which describe the ease of

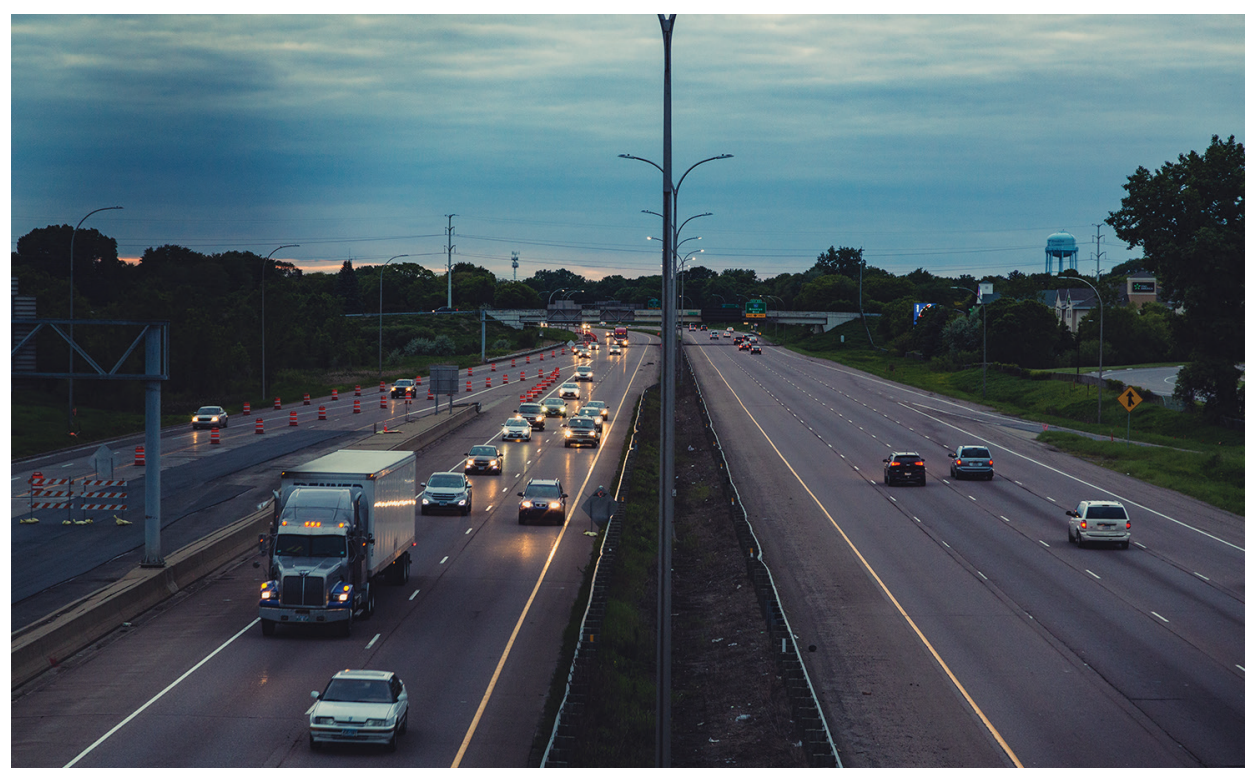

Congestion can tamp down some of the positive effects of urbanization documented in this study, including labor market pooling and the use of shared inputs among firms in unrelated industries.

reaching various destinations, as proxies for the types of sources of localization and urbanization economies described in the previous section, we examined the relationship between access and employment density by economic sector, looking to see how varying levels of access affected the propensity of firms in different sectors to agglomerate.

In constructing proxy measures for urbanization and localization, we drew upon employment data from the "Longitudinal Employer-Household Dynamics" (LEHD) data set, a publication by the Census Bureau that provides, among other tabulations, small-area counts of employment (at the census block level) that can be matched to workers' residential location at a similar level of geographic aggregation. The earliest year for which this data set was available was 2002. This employment data set was aggregated to the level of transportation analysis zones (TAZs), which are spatial units used to represent the region for travel forecasting purposes. The 2002 employment data set was linked with TAZs from the year 2000, and the associated network-level travel times between zones were used as inputs to the calculation of employment accessibility by zone. Measures of accessibility to all jobs within the region are considered to represent urbanization economies, while localization economies are more distinct in being sector-specific and much more spatially limited. Thus, localization economies were represented using measures of access to jobs in the same sector within 10 minutes.

This data set was used to estimate equations that relate the degree of agglomeration, represented by employment density, to our accessibility variables representing localization and urbanization. Separate equations were estimated for each of the two-digit economic sectors designated by the North American Industry Classification System (NAICS).

\section{Results}

We estimated separate relationships for the years 2000 and 2010, rather than combining the data into a single set, due to the differences in travel time estimation methods used in the accessibility calculations between years. Travel times for 2000 were generated using the region's travel forecasting model, while travel times for 2010 were obtained from direct observations supplied by a private data vendor (TomTom). The lack of comparability made it difficult to distinguish between travel time changes that appeared as a result of different measurement methods and genuine changes in the condition of the roadway network. To account for this, we reported the elasticities estimated for each sector and compared the relative rankings in each year. Intuitively, this suggests that we can know roughly how important urbanization or localization effects are for each sector relative to other sectors even if the exact magnitude is difficult to establish. These results are summarized in Table 2 . 
Table 2. Elasticities of Urbanization and Localization Economy Variables

\begin{tabular}{|c|c|c|c|c|c|c|c|c|}
\hline & Urbanization & $\begin{array}{l}2010 \\
\text { Rank }\end{array}$ & Localization & $\begin{array}{l}2010 \\
\text { Rank }\end{array}$ & Urbanization & $\begin{array}{l}2000 \\
\text { Rank }\end{array}$ & Localization & $\begin{array}{l}2000 \\
\text { Rank }\end{array}$ \\
\hline $\begin{array}{l}\text { Agriculture, Forestry, Fishing, and } \\
\text { Hunting }\end{array}$ & -0.064 & 20 & 0.704 & 11 & -0.228 & 19 & 0.759 & 8 \\
\hline $\begin{array}{l}\text { Mining, Quarrying, and Oil and Gas } \\
\text { Extraction }\end{array}$ & 0.399 & 16 & 0.571 & 12 & 0.611 & 14 & 0.420 & 14 \\
\hline Utilities & 0.592 & 14 & 1.863 & 1 & 1.156 & 8 & 0.691 & 10 \\
\hline Construction & 0.029 & 19 & 1.449 & 3 & -0.252 & 20 & 1.525 & 1 \\
\hline Manufacturing & 0.137 & 17 & 1.227 & 5 & 0.286 & 18 & 1.165 & 2 \\
\hline Wholesale Trade & 0.062 & 18 & 1.822 & 2 & 0.803 & 11 & 0.920 & 5 \\
\hline Retail Trade & 0.419 & 15 & 1.292 & 4 & 0.515 & 15 & 1.108 & 3 \\
\hline Transportation and Warehousing & 0.742 & 13 & 0.772 & 8 & 0.676 & 12 & 0.528 & 13 \\
\hline Information & 3.006 & 4 & 0.045 & 16 & 2.023 & 3 & 0.281 & 16 \\
\hline Finance and Insurance & 3.644 & 2 & -0.157 & 18 & 3.188 & 1 & -0.266 & 20 \\
\hline Real Estate and Rental and Leasing & 4.019 & 1 & -0.549 & 20 & 0.808 & 10 & 0.767 & 7 \\
\hline $\begin{array}{l}\text { Professional, Scientific, and } \\
\text { Technical Services }\end{array}$ & 3.339 & 3 & -0.230 & 19 & 2.561 & 2 & -0.114 & 19 \\
\hline $\begin{array}{l}\text { Management of Companies and } \\
\text { Enterprises }\end{array}$ & 2.223 & 5 & 1.010 & 6 & 1.452 & 7 & 0.814 & 6 \\
\hline $\begin{array}{l}\text { Administrative and Support } \\
\text { and Waste Management and } \\
\text { Remediation Services }\end{array}$ & 2.159 & 6 & 0.292 & 14 & 1.813 & 4 & 0.310 & 15 \\
\hline Educational Services & 0.798 & 12 & 0.569 & 13 & 0.501 & 16 & 0.557 & 11 \\
\hline Health Care and Social Assistance & 1.131 & 10 & 0.769 & 9 & 0.835 & 9 & 0.710 & 9 \\
\hline Arts, Entertainment, and Recreation & 1.419 & 9 & 0.960 & 7 & 0.468 & 17 & 0.934 & 4 \\
\hline Accommodation and Food Services & 1.941 & 8 & 0.114 & 15 & 1.641 & 6 & 0.167 & 17 \\
\hline $\begin{array}{l}\text { Other Services [except Public } \\
\text { Administration] }\end{array}$ & 2.143 & 7 & -0.054 & 17 & 1.800 & 5 & 0.069 & 18 \\
\hline Public Administration & 1.032 & 11 & 0.738 & 10 & 0.664 & 13 & 0.532 & 12 \\
\hline
\end{tabular}

Notes: The indicator of localization economy includes industry-specific jobs in the observed zones. The numbers in both shades of blue cells are insignificant at the $\mathrm{p}<0.05$ level.

The elasticities reported in Table 2 describe how responsive one variable is to a change in another. For example, the elasticity reported for the localization variable for the retail trade sector in 2010 (1.292) suggests that every 1.00\% increase in localization is associated with a $1.29 \%$ increase in employment density in that sector.

For 2010, the top eight sectors with the strongest urbanization effects include real estate, finance and insurance, professional services, information, management, administrative services, other services, and accommodation and food services. Except for management, the sectors tend to have very weak localization effects. On the other hand, the top five sectors with the strongest localization effects include utilities, wholesale trade, construction, retail trade, and manufacturing, all of which show weak urbanization effects. These results mostly align with basic (exporting) versus nonbasic (localserving) sectoral classifications (except manufacturing and wholesale trade).

The top eight sectors with the strongest urbanization effects in 2000 are similar to those for 2010. Real estate ranks highest in 2010 but ranks tenth in 2000. The specific rankings for other sectors vary slightly between 2000 and 2010. For localization effects, the sector with the largest change is utilities, which ranks first in 2010 but tenth in 2000. Arts, entertainment, and recreation join the top five sectors with the strongest localization effects.

Our findings indicate that in general urbanization effects tend to dominate localization effects across a range of economic sectors. This result tends to corroborate the findings of other studies that show few or no positive agglomerative effects from localization but significant urbanization effects at higher levels of aggregation, such as counties. Also, the magnitude of our estimates of urbanization and localization economies seem to vary significantly across 
economic sectors. In general, service sector employment densities tend to be most prominently correlated with high levels of accessibility. Sectors traditionally associated with central business district (CBD) locations like finance, insurance, and real estate and other sectors such as management of companies and enterprises, information, and arts and entertainment have the largest density elasticities. In contrast, sectors such as agriculture, mining, and construction tended to show a lower propensity to agglomerate.

\section{Implications}

The results generated in this study offer qualified support for the notion that high levels of accessibility may be linked to gains from agglomeration. Though they are limited by the cross-sectional nature of our data, the employment density regressions suggest that certain economic sectors, primarily those involved in finance, insurance, real estate, information, and arts and entertainment, may place a premium on being able to locate in places with high levels of regional accessibility.

From the perspective of transportation planning, these findings tentatively suggest that there may be a valid rationale for pursuing projects and policies that limit the effects of congestion on the region's roadway networks. To the extent that congestion reduces the accessibility provided by the network, it may affect the ability of firms to benefit from the types of urbanization effects documented in this study, including labor market pooling and the use of shared inputs among firms in unrelated industries. Improvements to the network that lower the cost of travel (including time) thus can expand the scope of markets and improve the matching process between firms and their workers, as well as customers and suppliers. Efforts on the part of planners to directly identify the sources of these benefits and incorporate them into project appraisal practices seem warranted.

The ideal metropolitan region would be both dense and easy to traverse. In practice, we tend to observe one of these conditions but not the other. Dense regions tend to have concentrations of employment that are physically closer to workers, consumers, and suppliers but that are more difficult to move through. The higher concentration of trip origins and destinations leads to higher traffic volumes on the network, which in turn leads to greater congestion-related delays. The benefit of physical proximity is often at least partially offset by the lower travel speeds attributable to congestion.

One possible way to overcome this problem is through the use of more widespread direct road pricing. Economists have long advocated for peak-period tolls on congested facilities as a way to address severe congestion problems. Tolls that vary by time of day, and hence travel demand, would have the effect of smoothing flows on major highway links, thus improving accessibility at exactly the time of day when it is needed most. A key component to making such a policy successful is continuing to reduce the cost of toll collection. While the transition from manual toll collection to more electronic forms of collection has advanced in recent years, the costs of revenue collection from tolling has remained well above that of alternative sources of revenue such as gasoline taxes, limiting its adoption.

The role that public transit networks might play in encouraging agglomeration is also subject to question. Our analysis of accessibility and agglomeration was focused heavily on travel via the regional highway network, mostly because it represents the dominant form of both passenger and freight movement in the region. We did make some attempt to look at accessibility via public transit as well but found it difficult to obtain independent estimates of the effects of public transit accessibility. Since most of the region's transit service remains bus-based, there tends to be a large amount of overlap between the region's highway and transit networks given that transit vehicles often share the same facilities as cars and trucks. It is therefore difficult to obtain estimates of transit accessibility that are distinct from those for the highway network and confounds efforts to statistically separate their effects.

Our study also leaves the door open to additional research on this topic. One major direction of research could be the collection of repeated observations of travel times for the region's transportation network. As mentioned previously, one of the limitations of our study was the use of two different sources of travel time data to produce accessibility measures for the two time points of our study, 2000 and 2010. Getting more observations over time from the same source would allow further analysis of the evolution of this relationship.

Moreover, it would be useful to explore the use of firm-level data (data at the level of individual establishments) in the relationship between accessibility and agglomeration. Our analysis suggests that high levels of accessibility are associated with employment density in specific sectors. However, we cannot yet totally reject alternative explanations such as firms in sectors with a greater propensity to cluster being co-located in places with naturally high levels of accessibility, as opposed to high accessibility causing greater clustering. These are important questions to continue to pursue, considering the possibly large returns from agglomeration. The efficacy of policies that might support agglomeration economies hinge on a sound and thorough understanding of their inner workings.

Jason Cao is a professor at the Humphrey School of Public Affairs at the University of Minnesota. His research interests include land use and transportation interactions, the effects of information and communication technology on travel behavior, and planning for quality of life.

Michael lacono received his Master of Urban and Regional Planning (M.U.R.P.) and Master of Science in Civil Engineering (M.S.C.E.) degrees from the University of Minnesota. His research interests center around travel behavior and transportation policy, planning and economics, with an emphasis on the evaluation of transportation systems.

David Levinson is Foundation Professor of Transport in the School of Civil Engineering at the University of Sydney. His research interests include accessibility, the co-evolution of transport technology and cities, and the political economy of transport.

Mengying Cui recently graduated with a Ph.D. in civil engineering from the University of Minnesota. Her research interests include accessibility evaluations and applications, transportation economics, and vulnerability of transport networks.

The University Metropolitan Consortium supported this research. 